\title{
Daribi kinship at perpendicular angles: A trompe l'oeil anthropology
}

\author{
Alberto CORSín JimÉnEz, Spanish National Research Council \\ (CSIC)
}

\begin{abstract}
What are the contours of such "knowledge" that does double duty both as a public good or commons and as a source of individual empowerment and liberty? This article offers an analysis of the epistemological organisation of the "knowledge economy" by shooting ethnographic work on Free Software through a playful trompe l'oeil of Roy Wagner's classic piece on Daribi kinship. It offers a preliminary template for thinking of EuroAmerican knowledge as itself a trompe l'oeil device.
\end{abstract}

Keywords: kinship, knowledge, commons, free software, perspectivism, perpendicularity, epistemology.

[T] he opposite of "kinship" is . . . total, unrestricted analogy.

Wagner, Analogic kinship: a Daribi example (1977)

Let us begin with the proposition that all forms of knowledge are analogous to one another. There are of course different kinds of knowledge. But we may think of these kinds as different expressions or manifestations of an underlying relational economy. In this economy, knowledge flows across and along different kinds of relationships-but it is the fact of its "analogic flow" that takes precedence and defines the underlying cultural logic. For in this system there seems to be a prerequisite and expectation that knowledge must be made to flow. Said differently, a "certain solicitude . . . is quintessential to all ideal [knowledge] relationships, regardless of how they may be defined or in what forms the solicitude is expressed. And this solicitude represents, as well as anything can represent, what I mean by the basic analogy of all [knowledge] relationships to one another.”

Acknowledgments: I am very grateful to HAU's two anonymous reviewers for their close reading of an earlier version of the article. Their comments have help made the argument much stronger. I am also thankful to Stéphane Gros for his patient and encouraging editorial work.

@ This work is licensed under the Creative Commons | (c) Alberto Corsín Jiménez. Attribution-NonCommercial-NoDerivs 3.0 Unported. ISSN 2049-1115 (Online) 
In this analogical economy, then, there is little profit in thinking of knowledge as being divided up into discrete units or entities. However and whatever knowledge is differentiated into, it will always be so from the starting premise of its analogical flow. Thus, "the flow of relationship, and ultimately lineality-analogy across the [epistemic forms]-is integrally linked to differentiation. Lineality is not a separate, 'political' consideration . . . but is always an aspect of a totality that includes differentiation as well." Such a totality is the underlying analogic flow of knowledge: the essential solicitude through which epistemic forms relate to one another.

Readers may recognize in the above a paraphrasing of the opening sentences in Roy Wagner's classic article, “Analogic kinship: a Daribi example” (1977: 623-24). Where Wagner spoke of "kinship," however, I have substituted the term "knowledge"; where he spoke of "generations," I have inserted "epistemic forms." That the organisation of knowledge may be modelled on an analogical economy of relations is, however, hardly a novel claim. The digital commons of the Internet's knowledge economy is the example par excellence. The commons is here actualized through a decentralized network of "knowledge-based communities" (David and Foray 2003: 21). The network enables “online exchanges" between diverse users, including designers, engineers or lay people on an equal footing, thus making it impossible to identify the exact location and identity of an innovation. The larger the number of people engaging in such peer-to-peer exchanges, the greater the chances of making the overall stock of knowledge grow. This is therefore an incremental model of knowledge-exchanges that relies on the very "wealth of networks" (Benkler 2006) as at once infrastructures for and analogues of knowledge. It is on this account that the networked economy of information may be seen as an analogical economy of knowledge, where activating a connection with a peer instantiates at once a relation and a flow (of bytes, files, information).

The analogical qualities of such a networked economy of knowledge have been amply documented and commented upon. It is often noted, for example, that the structure of networked information-and in particular the negligible costs of reproducing digital information-instantiates a de facto regime of superabundant or "open knowledge" (David and Foray 2003; Foray 2006: 172-79), where subsequent attempts at appropriating or circumscribing the flow of information would in effect amount to a "tragedy of the public knowledge "commons" (David 2000).

The commons of the knowledge economy may also be thought of as a system of externalisations. The image is derived from economists' own definition of public knowledge as, indeed, an externality: knowledge that, due to its intrinsic qualities, escapes proprietary circumscriptions, that "spills-over" market boundaries and enclosures (Cornes and Sandler 1996; Frischmann and Lemley 2006).

2 Wagner's piece opens thus: "Let us begin with the proposition that all human relationships are analogous to one another" (Wagner 1977: 623). As I hope to show in the rest of the article, the terms of the paraphrase, and the substitutions employed therein, are offered in the spirit of Wagner's original investigation into the work of "analogy." I am interested in what may internally configure "analogy" as an enabling epistemological device itself. I thank one of the reviewers of the article for prompting me to clarify the artifice of my opening analogy. 
Of course, what makes knowledge capable of "externalisation" is also what makes it "public." In its travelling as an externality, knowledge effectively detaches itself from itself: its very flow defines (and contributes to enhancing) the largesse of knowledge from wherein it has departed. In their analogically detached form, then, the flow of all such externalities through exchange is constitutive of the whole relational economy.

\section{The opposite of property}

Although there is considerable agreement today over the epistemic richness of knowledge in the wealth of networks, it seems a little harder to agree on its allegedly expansive qualities, whence the proliferation of liberal designations: open, commons, public. "Why do [some people] say the public domain is a commons?" asks critical legal scholar James Boyle. "Why [do others] use the term commons to refer to any resource protected by a liability rule rather than a property rule? Why [do they] refer to open source software as a commons, though it is in fact protected by a property rule?" The answer, he adds, "lies in the particular functions and dysfunctions of property on which the theorist is implicitly concentrating while creating their image of property's outside, property's antonym” (Boyle 2003: 29).

The liberal qualities of knowledge are therefore cajoled into existence, Boyle tells us, by “'the opposite of property'-its outside, its limitations, negations, inversions and correctives" (31-32). The practice of opposition would therefore seem an expansive terrain in itself, of which perhaps the most famous of its currents today might be the culture of hacking. Accounting for such a diversity of hacking practices, Gabriella Coleman and Alex Golub (2008) have recently described three traditions of hacker ethics: three modalities of exercising "freedom" or "liberalism" in cyberspace, setting up in each case their own complex negotiations with the world of property.

The tradition of crypto-freedom, for instance, promotes "an ethical sensibility that affirms the sacrosanct nature of individual privacy" (ibid.: 260). Thus, the concern of the volunteer association Cypherpunks is to protect individual autonomy from intrusive corporate behaviour, including governments, and in pursuance of this aim they develop technological solutions for securing personal privacy in the world of digital information. Whilst Cypherpunks are thus concerned with guarding freedom from institutional intrusion and coercion (known in political theory as "negative freedom"), Free Software advocates promote instead a "liberal version of freedom that invoke[s] the virtues of sharing and pedagogy"-thus a "more positive notion of liberty" (261). Moreover, the essential freedom that inheres in information imbues the practice of programming among Free Software developers with an experience of artistic and creative selfexpression: a "romantic drive" for creativity whose goal is to enrich the awareness and bonds of communitas among fellow developers (263).

Last, the ethics of the so-called "hacker underground" is characterized by a radical culture of transgression. Their moral practices engage in an ongoing struggle over the means and technologies that work to consolidate power. As Coleman and Golub put it, the "underground seeks to remind those in power that there are individuals in an unknown, cavernous 'out-there' who can and always will unsettle, even if only temporarily, the purported absolute power of the establishment'." The underground cherishes the thrill that derives from "the 
aesthetics of eating forbidden fruit into the human art of the short con" (264), an excitement that is expressed in idioms of pleasure, passion for exploration, even humour.

The three moral genres of hacker practices therefore enact very different "opposites to property." Coleman and Golub suggest that in the American context the hacker material may in fact be read as "a cultural case in which long-standing liberal ideals are reworked in the context of interaction with technical systems to create a diverse but related set of expressions concerning selfhood, property, privacy, labor, and creativity" (267). As an ethnographic insight, the opposite of property would in this context seem to emerge from/as an American tradition of romantic individualism, liberty and freedom. Although it is certainly not their interest to reify a notion of American Culture, overall Coleman and Golub's study suggests that the techno-cultural form of hacking stands in a "dialectical relationship" to the general cultural template of liberalism (267).

James Leach has also carried out work among Free and Open Source Software (F/LOSS) programmers, and his ethnography focuses likewise on the morality and aesthetics of freedom and liberty at play among developers (Leach et al. 2009). His interests, however, lie in the processes of emergence of "freedom" as a social form and action. Not, then, on the kinds of techno-cultural forms that stage a dialogue with, and contribute to, ongoing conversations about the qualities of liberalism, but on the internal enablement of hacking itself as an emancipatory form.

A number of elements play a part in this entangled process of enablement. ${ }^{3}$ For one, hackers make serious investments in writing good code. Good code is code that works, which brings about the effects wished-for in the "external world." Leach says that hackers have a "binary' approach to judgement," by which he means that in writing good code hackers are ultimately concerned with writing programming language that is machine-truthful. The goodness of code evinces in it being machine-readable. If the programming language is true, then the code will be good: "judgements of fitness or effectiveness merge with more subjective aesthetic judgements." This binary form of judgment, Leach suggests, may be read as a "metonymical extension" of the binary code (zeros and ones; on and off) upon which all computing programmes run (58-59).

If the natural morality of good code appears to uphold itself on the natural veracity of language statements, there are however certain forms of cultural exchange that help elicit such truthful code-facts. Leach points for instance to the practice of "flaming," which involves the heated and rancorous exchange of messages between developers in public forums (60). Such tournaments of agonistic exchange are thought of by the F/LOSS community as occasions that contribute towards the making of more robust code. Code thus achieves the status of a selfevident "Good Thing" (61) when it can survive comparison and the agony of vociferous contrast.

As a form of knowledge then, F/LOSS stands at the very frontier of our epistemic futures. The robustness, effectiveness and intrinsic goodness of F/LOSS translates into a sociologically self-evident potentiality: whose beauty, simplicity and effectiveness awaits all sorts of applications and eventful futures. As Leach puts it,

3 Leach reminds us that "enablement" is a self-descriptor used in F/LOSS (Leach et al. 2009: 55 and 69, fn. 5). 
"because code both enacts knowledge and makes knowledge evident, in an illocutionary way it reproduces the imagined space of a frontier by revealing the truth of what exists and thus new potentialities" (62). It is of course this sense of immanent futurity that informs the liberating and liberal qualities of F/LOSS as an epistemic object; that enables from within its projection as a political heir to and vehicular form of liberalism. Working upon code is analogous to working upon society. Every bit / byte that works fuels emancipatory social change.

\section{Analogy}

I opened the article with a paraphrase of Roy Wagner's classic essay on analogic kinship. I would like to return to that piece again. At the end of my introductory section, I noted how in the imagination of the new digital commons, "the flow of all such externalities through exchange is constitutive of the whole relational economy." This sentence, too, was a paraphrase from Wagner's piece, who at one point observes that "the 'flow' of controlled analogy through exchange is thus constitutive of the whole relational matrix" (Wagner 1977: 631).

What Wagner calls "controlled analogy" are "detached, partible things" (souls, women, pearlshells, meat) that circulate among Daribi kinsmen in their efforts at creating distinctions between kinds of persons and relationships. The flow of such analogical objects is controlled because what is at stake here is the lineality of kinship. Let me explain.

Wagner makes a distinction between "vertical" or "lineal" and "horizontal" relationships. Vertical relationships, and vertical analogues, are those that contribute towards the life-sustenance of female and male lines. However, whilst femaleness is considered to be self-sufficient, the role of maternal blood (pagekamine) enough for conception, maleness is deemed on the contrary contingent. The seminal fluid (kawa) of a man is never sufficient for conception and must be augmented by the juices and fat of meat. As Wagner puts it, meat is "an adjunct to maleness and male reproductive potential: it is the partible and portable accessory to masculine continuity." The conceptual world of Daribi kinship is therefore organized through the flow of substantial and partible analogues, although the moral force of the flow is in effect always represented and perceived as the "lineal flow of male substance" (628).

Thus, for example, the parties to a betrothal are not simply engaged in a ceremonial exchange of prestations, but are striving to secure the continuity of their respective linealities. The objects exchanged are "adjuncts of female productivity (bark, cloth, string bags, and so forth)" in one case, and flows of maleness itself in the other, "giving meat and other adjuncts of maleness and male productivity (pearlshells, axes, bushknives)" (ibid.). The horizontal flow of such detached markers at once supplements and zooms in on the vertical flow of relational analogies (kawa and pagekamine). Objects flow horizontally and in so doing promote or enhance the vertical flow of substances. They analogize each other at perpendicular angles. In Wagner's words: "Exchange and descent, affinity and consanguinity, become metaphors for one another" (632).

Analogies thus work within and across social forms. Vertical flows are analogous to horizontal exchanges; but verticality and horizontality are themselves internally analogized by mutual cross-references. Thus, pearlshells or meat flow horizontally to replenish and augment their verticality. The paradigmatic case of 
such an analogical duplex ordo is the birth of a child, who "becomes itself a point of analogic relation between the two linealities: relationship has 'happened' to the original demarcation between them. Because the same social persona stands in an analogic relation to both, the two are related analogically to one another" (634). A matter to be resolved then is the lineality (maternal or paternal) to which the child belongs. Although both sides see the child as a potential analogue to supplement male contingency, it "becomes a truly pressing issue for the father's lineality, since for them male contingency is opposed to female sufficiency" (634). It is the paternal side, then, who claims the child through the presentation of a detached analogue for substantial flow (pagehabo). But the flow of analogies accomplishes a further analogy, for "inasmuch as the persona for whom the payments are given belongs simultaneously to both linealities, and relates them, the mediating payments that define this lineal affiliation are exchanges within a single lineality. They are 'shared' as well as exchanged" (635).

Sharing and exchanging emerge in this context, therefore, as analogies of an analogy. From the point of view of the father's line, the presentation of pagehabo expresses sharing (the amplification and distribution of kawa, now passed down the male line) through the idiom of exchange (mediating payments). From the point of view of the maternal line, it expresses exchange (mediating payments) through the idiom of sharing (the self-sufficiency of the child's femaleness, which now supplements male contingency).

Importantly, however, the circulation of pagehabo is seen simultaneously as a vertical and horizontal flow by both kinship lines. What the paternal line sees as a vertical flow (the flow of kawa), the maternal line will see as a horizontal flow, and vice versa. As noted above, we may therefore say that the flows are analogized at perpendicular angles with respect to each other. Alternatively, the flow of analogies effects an exchange of axes: as they move along the axes the analogues (meat, pearlshells, etc.) are at once "separating/holding parts of itself/things from one another/together (the sentence can be read in two ways, as indicated by the italics threading one of them)" (Strathern 2005: 163n3). At any moment during a transaction, any one analogue is keeping the axes differentiated (the vertical from the horizontal; the paternal from the maternal) and collapsing them onto a single lineality. "It is," in Wagner's words, "like virtually everything else in the relationship, ambiguous, and it acquires this character precisely because the relationship, qua relationship, is constituted by the summing together and mutual modelling of the two aspects" (Wagner 1977: 636).

\section{Trompe l'oeil}

Around 1670, Dutch artist Cornelius Gijsbrecht produced a number of paintings that played on the rhetorical power of perspectivalism to startling effect. Trompe l'oeil letter rack, for example, masterfully displays a three-dimensional letter rack that bodies forward in space. As in all trompe l'oeil paintings, we are tricked into seeing a number of objects that apparently hang out from the picture plane and invade our own physical space. The trick is here twice enfolded, because some of the letters and papers hanging from the rack are partially hidden or veiled by a curtain. The curtain supplements the perspectival trick: it generates a false sense of depth in a painting whose entire mission is to empty itself of depth. The illusion of 
the trompe l'oeil is sustained by making us believe that the objects are outside rather than inside the pictorial plane.

Hanneke Grootenboer has commented on this painting by Gijsbrecht and other seventeenth century Dutch trompe l'oeils, a propos their capacity to turn perspective inside out (Grootenboer 2005: 54). In trompe l'oeil paintings, she argues, the vanishing point and the point of view are made to coincide. Thus, rather than being invited into the picture, our perspectival gaze is in both cases forced instead to bounce off the picture plane. The "vanishing point to which the viewer's eye is directed," writes Grootenboer, "can never be reached-or, for that matter, seen-and collapses with the point of view from which seeing is made possible" (54). We think we are looking at a perspectival painting and yet we are not allowed to rest our perspectival gaze at its natural resting place: the vanishing point. Our perspective is instead violently thrust back to us, or as Grootenboer puts it, is "turned inside out".

Trompe l'oeil paintings are a meeting place for what, following Lacan's famous description in Seminar XI, Grootenboer calls the reversibility of the gaze. The surface of a trompe l'oeil painting captures the encounter of the vanishing point and the point of view: where the perspectival organization of painting displays simultaneously an inside/outside structure. She offers an eloquent description of how this structure operates with the example of a glove:

If we turn the finger of a glove inside out, its structure will remain exactly the same but will now be articulated by its reverse side. Previously enveloped by the leather, the lining of the glove will emerge. Exteriority and interiority are reversed without actually changing the structure of the glove. Elaborating on this metaphor, we may imagine the tip of the glove's finger as a vanishing point that once pulled out reveals the other side of the point, which normally falls beyond the horizon. Moving the finger of the glove back and forth, we see how the vanishing point can merge with the point of view when the structure within which these points are normally separated is mapped out (55).

The surface of a trompe l'oeil painting therefore becomes a meeting place for two perspectives: the perspective that is hollowed out in a forward direction from the painting's interior and the perspective held by the viewer from outside the painting. We can no longer speak of a vanishing point and a point of view, for these are descriptors that properly belong to the tradition of linear perspectivalism: inside a painting and outside a painting are epistemological locations defined within the parameters of a classical Renaissance geometrical grid.

One could venture instead the argument that what is in effect making an apparition in the trompe l'oeil painting are two distinct pictorial objects: one canvas, two pictorial forms. If we follow Grootenboer's metaphor, the inside of the glove's finger is a different object from its outside. They are objects that share a perspectival structure-they both have a point of view on what is inside / outside in each case-but they are ontologically distinct objects. These are not objects differently located within the same geometrical plane, but objects which summon different topological fields. Another painting by Cornelius Gijsbrecht can help illuminate this point.

In The reverse side of a painting (c. 1670) Grijsbrecht presents a painting whose canvas has been turned around. 


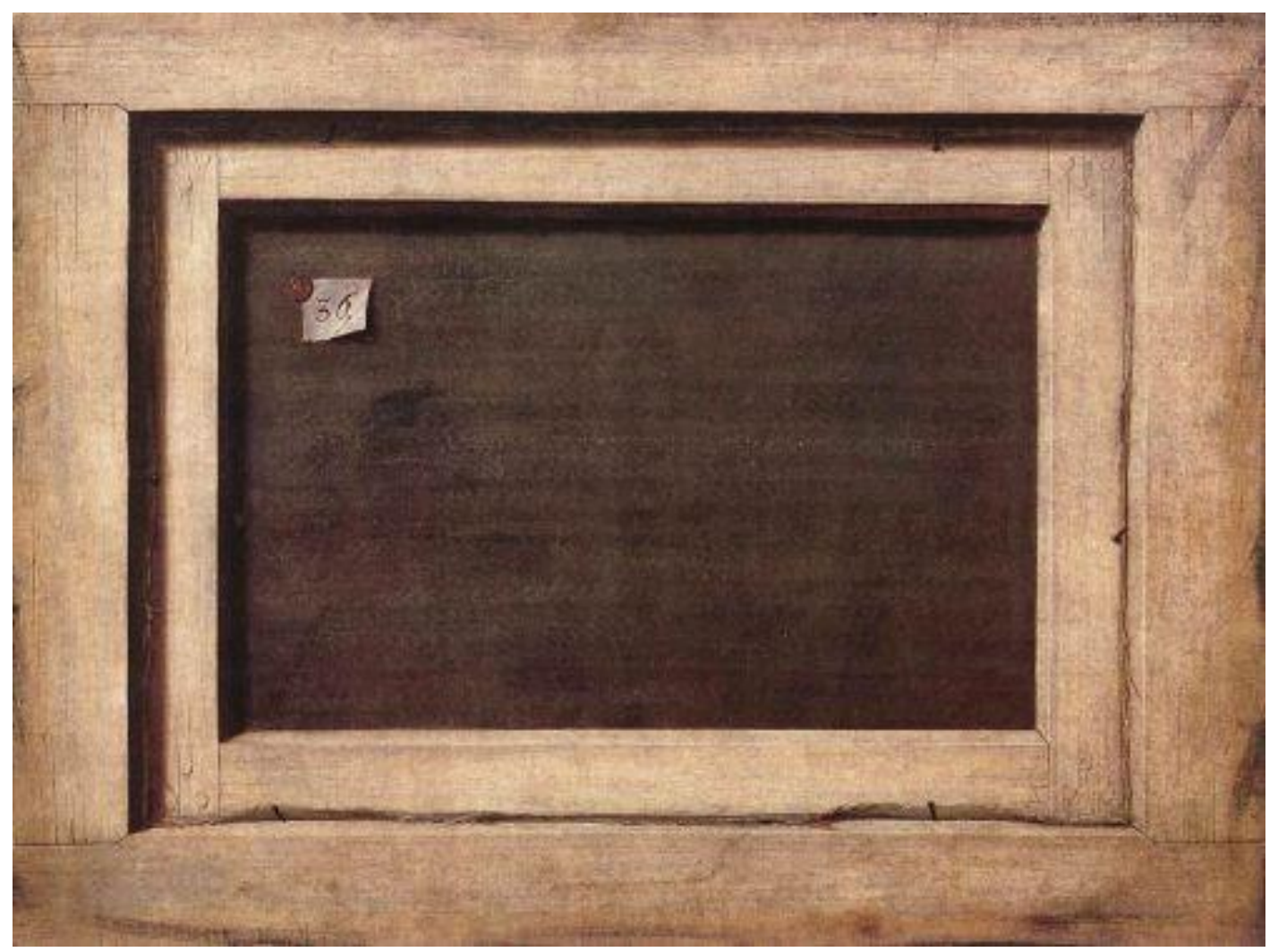

Figure 1. Cornelius Gijsbrecht, The reverse side of a painting (c. 1670), Statens Museum for Kunst, Copenhagen.

We see a wooden stretcher, six nails holding the frame in place, and the back of a canvas proper. But there is of course no image. Grootenboer has nicely described the viewer's startled reaction when confronted with this picture:

If we follow our inclination to turn this canvas around in order to see what is represented on its front side, its shock effect would reside less in the deception, and more in the discovery that there is nothing there to see. Nothing, except for the same image, back as front (59).

The picture whose negation Grijsbrecht painted is of course a different object from the actual frame and stretcher we would encounter if we were to flip the painting around. They hold the same perspective (they index the same presentation of the world: the reverse side of a painting) but they do so from distinct epistemological and ontological positions: a human- and an object-centred point of view. Thus, whereas The reverse side of a painting is the view we hold of the picture as viewers, that is, a view that obtains through an epistemological action (the act of eliciting the painting as object), the back side of the painting, on the other hand, elicits not an epistemological point of view, but an ontological position: an object (the wooden stretcher) that no longer requires the epistemological elicitation of a viewer to come into existence. The reverse side of a painting and the reverse side of a painting are therefore different epistemological and ontological points of view, respectively, on the same epistemic object. 
The reverse side of a painting's masterliness lies in Gijsbrecht's sophisticated problematization of the representational strategies of the linear perspectivalist tradition. Like Velazquez's Las meninas or Vermeer's The art of painting, it is a cunning work of baroque intelligence that subsumes its representational motif in a dazzling display of double relations (inside : outside / object : human / epistemology : ontology), and in so doing endows the notion of the duplex itself with epistemic status. The reverse side of a painting calls out the reverse side of a painting: the painting and the wooden stretcher mutually require each other for completion. At the same time, completion as such never quite obtains, for it always depends on one additional reversion, another flip of the object. The object therefore inhabits and performs an aesthetic of permanent elicitation.

Gijsbrecht's boldness forces us to take residence in the epistemic space of the painting's liminal screen as a guarantor and purveyor of reasonableness. Oscillating between an interior and an exterior perspective, an ontological and an epistemological point of view, the trompe l'oeil's very reversible structure emerges therefore as the only possible comfort-zone for stabilizing, if in a transient and fragile manner, the turbulence and confusion of all such double movements. It is the painting's reversibility that holds all such reversions meaningful, much like perpendicularity does for the relational matrix of Daribi kinship. If reversibility operationalizes the task of conceptualisation for Gijsbrecht's baroque reason, perpendicularity does so in Wagner's axial world, where the horizontal elicits the vertical, and vice versa. Reversibility / perpendicularity is a concept that allows us to flip between an epistemological and ontological point of view.

\section{At perpendicular angles}

Gijsbrecht's trompe l'oeil baroque cunningness reminds us of the Daribi flow of analogies at perpendicular angles. We may remember how in Daribi betrothal prestations the vertical flow and the horizontal flow were each a "model 'of' and model "for" one another (Wagner 1977: 631). In this mutual self-containment, the work of the analogical resembles therefore a sort of trompe l'oeil effect, whereby the horizontal (say, the perspectival vanishing point) collapses onto the vertical (the self-standing point of view). The vanishing point is hollowed out in a forward direction and made to coincide with the point of view. The surface of the trompe l'oeil canvas contains thus two perspectives (the vanishing point and the point of view) within a single lineality (the surface of the trompe l'oeil painting itself), not unlike how a Daribi "controlled analogue" allows for conceptual flips between the horizontal and the vertical, the paternal and the maternal, sharing and exchange, kawa and pagekamine, "within a single lineality" (ibid.: 635).

Eduardo Viveiros de Castro has recently produced an original analysis of anthropological theory (an anthropological theory of anthropological theory) that echoes some of the baroque motifs and aesthetics of the trompe l'oeil technique. He has described the transformational conditions of anthropology as the "discursive anamorphosis of the ethnoanthropologies of the peoples thus studied" (Viveiros de Castro 2010: 17, emphasis added). A word on the relation between the anamorphic and trompe l'oeil in this context is therefore in order.

An anamorphic projection is one in which the point of view and the vanishing point of / on an object are deliberately disjoined. We look at a painting but our gaze finds no rest in its vanishing lines and objects. It bounces off the canvas and is 
thrust back upon us. When looking at one such painting one therefore requires the use of a special device (say, an optical lens) or manoeuvre (for instance, approaching the painting at a skewed angle) to restore the alignment of the vanishing point and the point of view, and thus the proportional semblance of an otherwise distorted projection.

Thus, in front of an anamorphic painting our subject position is determined by the point of view itself: We may opt to take a position perpendicular to the painting's surface, in which case the anamorphic projection will appear smeared and distorted. We will be seeing nothing. In effect we would have therefore opted for assuming a subject-less position: the position from wherein nothing becomes visible. Alternatively we may engage with the painting and attempt to assume its own point of view. This might require our bending the lamina or coming up close to the canvas and skewing our vision diagonally across its surface. Slowly, gradually, the anamorphic distortion will recompose. The painting will disclose and elicit its own point of view. We will now be seeing the distorted image but it will have become visible "from the painting's point of view" (Grootenboer 2005: 131). We may therefore say that anamorphosis and trompe l'oeil techniques both work as analytical devices that elicit "perspectivalism" itself as an analytic. ${ }^{4}$ A point of view on/of the point of view: the perspective's perspective. ${ }^{5}$

Although neither anamorphic paintings nor trompe l'oeils necessarily require the splitting of the vanishing point and the point of view at perpendicular angles, ${ }^{6}$ the image of the perpendicular split is useful nonetheless as an analytical heuristic. Not surprisingly, Viveiros de Castro has resorted to this image in his elucidation of how an anthropological anamorphosis functions in his own models of Amerindian perspectivism: "Amerindian perspectivism," he notes, "is an intellectual structure that contains a theory of its own description by anthropology; because, that is, it is itself an anthropology situated at a perpendicular angle with respect to ours" (2010:

4 Here I follow Marilyn Strathern's useful recent convention, where she distinguishes between "perspectivalism" and "perspectivism." The former "rests on a mathematics that seeks to resolve the world into discrete entities," whereas the latter "implies an ontology of many worlds" (Strathern 2011: 92). The former enacts a plural world, the latter multiple worlds. See note 4 below for some additional comments on the "perspectivalist" vs. "perspectivist" distinction.

5 Although I cannot offer a full elaboration of the epistemology and heuristics of "perspective" here (see Corsín Jiménez 2011), I shall briefly point out that as a general epistemic device, the work of perspective does not accommodate itself to a simple dichotomy between classical Renaissance or Cartesian "perspectivalism" and Amerindian or, indeed, Daribi "perspectivism." For a start, the modern tradition carries a split within: the work for example of Baroque (anamorphic, trompe l'oeil) perspective is very different from that of Cartesian perspective. Indeed there are arguments, and Hanneke Grootenboer's wonderful book is an example, that suggest that the whole structure of "perspective" is fuelled from within by a rhetorical or allegorical power (Grootenboer 2005: 163). It is the baroque form or expression of perspective that shows that all perspective is in fact allegorical. What merits attention, then, is how this allegorical power travels when adopted as a heuristic by recent anthropological theory-what enables the anthropological form of "perspective" to be internally organized as allegory?

6 An anamorphic projection may not require an exact $90^{\circ}$ (perpendicular) adjustment of our point of view to bring the image back into its proper shape. 
60, my translation). The "perpendicular" is of course also the neatest exposition of how the "relational matrix" of Daribi kinship obtains when the vertical and the horizontal cross axes.

In his recent book, Cannibal metaphysics (2010), Viveiros de Castro offers an original reinterpretation of Wagner's model of Daribi kinship in terms analogous to the perpendicular perspective offered here. He picks up on Wagner's description of kawa and pagekamine as "simply two ways in which the vertical flow of analogy" may be represented. Mutually analogized at perpendicular axes, we may recall, these "amount to the same thing seen, as it were, from different angles" (Wagner 1977: 628). Viveiros de Castro follows up on this remark by observing that in the "interpretation of Melanesian gift-exchange as being defined through the tension of an exchange of perspectives... it is the notion of perspective that determines conceptually that of exchange, and not the other way around" (2010: 133, my translation). What looks like the flow of kawa from one angle is seen as a flow of pagekamine from a different axis. The exchange of prestations is therefore elicited by this mutual analogising of the same thing from different points of view. It is the angular aperture, so to speak, that makes the elicitation visible.

My overall point, then, would be to draw one further analogy: between the flow of analogies, the exchange of perspectives, and perpendicularity itself (the angular aperture) as a trompe l'oeil effect. What Viveiros de Castro calls an "exchange of perspectives" performs the same function to what I referred to earlier as an "exchange of axes." As my detour through Cornelius Gijsbrecht's work brought into focus, however, the substitution or displacement of "axes" for "perspectives" brings to the fore the purchase of perpendicularity itself as a concept. In Gijsbrecht's paintings, the canvas' surface both gathers and keeps distinct, in properly baroque and ambiguous fashion, the horizontal (vanishing point) and the vertical (self-standing point of view) axes. When views meet, the axes collapse, and the perpendicular emerges. The surface of the trompe l'oeil painting becomes therefore a meeting place for two perspectives/axes. Analogously, we might say that in the encounter between an Amerindian vanishing point and a Daribi point of view, the perpendicular is what surfaces as the very concept of anthropological analogy.

\section{Enablements}

In the terms in which Wagner carries out his analysis, the flow of "controlled analogies" delineates kinds of relationships whose "essence" constitutes the kinship "system." Kinship is the flow. As such, the analogues/analogies that flow are always partial versions of much larger analogical economies: an analogy is always an analogy of something else. That is why kinship surfaces as a controlled flow, for if the "essence of 'kinship' is restriction . . . the opposite of 'kinship' is therefore total, unrestricted analogy” (Wagner 1977: 639).

7 Note that the substitution of "axes" for "perspectives" is already insinuated in Wagner's piece, when he observes that kawa and pagekamine "amount to the same thing seen, as it were, from different angles" (Wagner 1977: 628). The word "angle" invokes the perpendicularity between the horizontal and the vertical. At the same time, however, these axes suddenly emerge as simultaneously enabling situated points of view ("things seen from”). 
In the knowledge economy, the analogue is the "externality"-the form of knowledge that self-detaches (spills over) itself and in so doing contributes to the largesse of public knowledge. ${ }^{8}$ Knowledge is the flow. Thus, if the opposite of kinship in the Daribi conceptual world is total unrestricted analogy, such totality, in the Euro-American knowledge economy, obtains at the expense of property. The opposite of property is total, unrestricted access to the knowledge commons.

Working our way down from an idealized and unrealizable knowledge commons into the partial analogies that sustain it is, of course, what the task of an anthropological analysis ought to amount to. ${ }^{9}$ Unlike legal scholars, for instance, who tend to populate the detotalization of the commons with property rights and licenses, anthropology would turn instead to what Coleman and Golub called its techno-cultural forms, and what Leach dubbed its forms of enablement.

Coleman and Golub's ethnography elegantly reminds us that when information is at stake, our Euro-American liberal tradition finds it close to impossible not to theorize its practices of self-description as practices of democratic and ethical selffashioning. Our theories of knowledge are theories of political ethics (Corsín Jiménez 2008): we own up to our information in the same terms through which we describe-i.e. analogously to-what we owe to each other. ${ }^{10}$ Sometimes we privilege privacy, sometimes we honour communication; sometimes we take pride in individual autonomy, sometimes we elaborate on the virtue of pedagogical

8 What kind of epistemic objects fulfil the conceptual imagination of public knowledge as an externality? Mathematics is the example preferred by economists (for example, Stiglitz (1999: 308) and Foray (2006: 114-15).) Once a mathematical theorem is made public, no one can be directly excluded from learning it, nor can they be taken the knowledge away once they have learned it. (An underlying assumption here is that people have the skills to learn the theorem. The assumption is problematic.) The knowledge is "external," has escaped its conditions of production, is free to travel, and is available also for anyone to consume.

9 After Wagner, who notes that "an (unrealizable) ideal of total analogy is detotalized and distributed over a range of partial realizations, each corresponding to a kind of relationship. A kind of relationship (designating the particular kinds of relatives proper to it) can then be considered as an analogue of relationship in general, diminished and restricted in certain dimensions so as to control and channel the flow of relational analogy" (Wagner 1977: 639). If the knowledge commons is our total (idealized and unrealizable) analogy, what are its partial realizations?

10 Tony Crook has described the internal equation of knowledge with the social in terms that I find particularly illuminating: "One root of the problem here is a peculiar euroamerican habit of eliding the solidity of a social relationship with the solidity of knowledge-and then taking one as a measure of the other" (Crook 2007: 10). Note that what is reciprocally "owned" here is "the social" as an epistemic form. We might say that the flow of knowledge lends the social a certain tangibility. The result is not to be confounded with what Marilyn Strathern calls a transactional regime (not unlike the organisation of Daribi exchanges): "Transactions thereby create a form of 'multiple ownership'. In so far as they determine what is transactable they can also determine the parties to the transaction. Thus 'groups' may 'emerge' at the time of the interchange itself, identified as parties to the transaction. The gaining and disposal of things do not extinguish the parties' mutual interest in the things or in one another: in 'owning' the flow of items they 'own', as an intangible thing, the relationship between them" (Strathern 2006: 454, emphasis added). 
transformation. Knowledge is both a means of transgression and an endpoint for romanticism. It is the Euro-American analogy par excellence of self and other. It does both vertical work (enhancing or supplementing our ethical pedigree) and horizontal work (a commodity that mediates further transactions). It fares as both theoretical commodity and methodological infrastructure. As Charlotte Hess and Elinor Ostrom have put it, it has "dual functionality as a human need and an economic good" (2003: 13). Knowledge is our (what we have in) common(s), a point to which I shall return in the conclusion. Thus, in the world of software, there are those, as Chris Kelty puts it, that see software as a product and those that see it as "part of the human itself, constitutive of our very freedom and, hence, inalienable. Extending software, through collective mutual aid, is thus tantamount to vitality, progress, and self-actualization” (Kelty 2008: 309).

It is in this context that I find particularly useful James Leach's study of F/LOSS in terms of enablement. Hackers, Leach observes, work with a binary form of judgment. This simple binarism compounds an ethics and a pragmatics-it offers justification both for moral and rational action, and in so doing generates the conditions of possibility for future actions. Such a binary model locates the actions of hackers in an infrastructural media-the media of the Internet. It is the binarism of the Net that mediates the social hopefulness of collaborative work. It is the "naturalisation" of machine language that gets "metonymically" extended by programmers into a module of "external reality" (Leach et al. 2009: 58-59). The machine capillarizes the world.

Leach sees some cause for concern in F/LOSS's binary form of judgment. Its pragmatics of truth-hopefulness, he intuits, are anchored on a form of moral reasoning based on the individual:

The personal and the moral interlink in the activity of writing F/LOSS code. Pursuing one's craft is also to behave ethically and to have a positive influence in society. The moral is presented as if it were merely an outcome of writing source code and fulfilling one's personal ambitions. ... Ethics and politics are pursued through making material objects which then in themselves, without the need for 'social' action, achieve political ends (64-65).

Moreover, the culture of binarism flourishes on public and "flaming" tournaments of arrogance and bravado. According to Leach, in this context, what the culture of free software liberates is for the most part flows of maleness-women being conspicuously underrepresented in F/LOSS communities. The body of the freedom coder, it seems, is a male one.

Binarism, however, summons forth a second kind of relation: the Network/Machine as a social relationship itself. Chris Kelty (2008) has offered what is perhaps the most comprehensive ethnographic account to date of the infrastructural and sociological dimensions of Free Software, and their entanglement in the production of what he calls "recursive publics." What distinguishes a Free Software community from others, according to Kelty, is the work of "modulation" they lend to their own infrastructural capacities. They work on themselves by working on (writing code, editing, patching, compiling, improving) their infrastructure. Their capacities to act are therefore infrastructural capacities, in that it is the recursiveness of code as both a social and machine element that animates collective action. In Kelty's words, "Geeks create and 
modify and argue about licenses and source code and protocols and standards and revision control and ideologies of freedom and pragmatism" because these things "are reconstituting the relationship between liberty and knowledge in [our] technically and historically specific context” (2008: 10). Freedom, in other words, is sourced in the infrastructural equipment that furnishes the modern subject's capabilities for social (network-mediated) action. This is of course an extendible or expansible notion of freedom, inasmuch as an agent's capabilities for free action derive from the ongoing infrastructural transformation of the Net/Machine itself. With every "add-on," freedom is recursively expanded. Our freedom depends on the Net's own temporality as an infrastructure. ${ }^{11}$

\section{Conclusion: Wide angle binoculars}

The entanglement of the Net/Machine's temporality as an expandable horizon and our (net users) sense of freedom and enablement, throws into sharp relief, I would like to suggest, some aspects of our contemporary Euro-American conception of knowledge. Our sense of freedom as an epistemic enterprise delineates in one and the same move both the horizon of our social world and the political epistemology for its cognizance. We are defined as politically cognizant subjects by the Net/Machine's own social relationality. What the Net intuits as potential freedom the subject interiorizes as epistemic knowledge. The ambit of our horizontal, netmediated exchanges 'flows as an analogy' of our vertical, autonomous sense of liberation / liberty. Knowledge is what we have in common.

In the terms of the trompe l'oeil anthropology I have sketched above, what this implies is that it is the Net that perpendicularizes every knowledge-effect. It is the Net that mesmerizes us with its trompe l'oeil surface. The Net proliferates the points of view on/of knowledge.

In this light, one is tempted to suggest that it is the Net/Machine, too, which deploys the image of knowledge as both an encompassing and encompassed object: it is the Network that tricks into view the allure that the Commons exercises over the imagination (its futures, promises and liberating potentials-its vanishing points), as well as the Network that affords concern over "narrower" issues, over bytes, licenses, privacy and rights of access (its objectives, properties and standards-its points of view). Of course this is the point made a while ago by Annelise Riles (2001)-that the Network may be "seen twice." For Riles, the network refers "to a set of institutions, knowledge practices, and artifacts thereof that internally generate the effects of their own reality by reflecting on themselves" (3). The Network's internal relationality (as an infrastructural network) defines the subject's internal conception as a relational and social person. As she puts it, "networkers deploy the optical effect of Network form as a 'fulcrum or lever' that generates alternative inverted forms of sociality by projecting an image of eachNetwork and 'personal relations'-from the point of view of the other' (115-16,

11 Kelty thus observes that the question of Free Software's "modifiability" (its source code being available for reuse and transformation) "raises a very specific and important question about finality. When is something (software, a film, music, culture) finished? How long does it remain finished? Who decides? Or more generally, what does its temporality look like, and how does that temporality restructure political relationships?” (Kelty 2008: 11). 
emphasis added). A baroque device like no other, the Network's trompe l'oeil surface holds an alternation of points of view within a singular optics.

Chris Kelty describes such optical effects alternatively by noting that the "singularity of the Internet is both an ontological and an epistemological fact" (2008: 306). My aim in this article has been to try to elucidate the internal organisation of the epistemic form that allows for such duplex descriptions. I have shown how the epistemological organisation of "perspective" is fuelled from within by what Hanneke Grootenboer calls the engine or form of baroque allegory (2005: 163). I have further traced such allegorical effects in the "axial," "anamorphic" and "optical” heuristics employed by Wagner, Viveiros de Castro or Riles. An underlying concern throughout has been to understand what enables the allegorical form of perspective to travel as a modern anthropological device (see also Corsín Jiménez 2011).

Recently Marilyn Strathern has analysed the duplex qualities of Euro-American knowledge and exposed the role played by "science's relation" in the organisation of its epistemology: where the concept of the "relation" does double work as both discoverer of existing co-implications and inventor of new connections (2005: 3349). "The relation," for Strathern, is the epistemological device that self-describes and transforms the modernist project.

Here I have sought a similar yet not-quite-replicated effect, in that EuroAmerican epistemology is caught by surprise and entrapped in a pictorial/allegorical manoeuvre. This playful surprise has led me to unearth in turn a role for "perpendicularity" in the internal configuration of such epistemology. What anthropological form must knowledge take if it is to produce duplex/optical/ reversible effects? A tentative answer suggests that it might be a form of (Daribi) kinship at perpendicular angles.

At perpendicular angles there is another quality of knowledge that is made visible, namely, knowledge's own angular effects. I build here on a recent piece by Marilyn Strathern (2011), who has picked up on the binarism that characterizes Euro-American knowledge practices at large. It has not always been noted, Strathern observes, that in this epistemology "distinctions easily contain or lead to other distinctions" (91). Knowledge self-analogizes itself through ongoing bifurcations. Every new analogue of knowledge faces a wide open terrain wherein to analogize itself further: "there is a kind of arithmetic here that unitizes or individualizes the concepts that drive arguments-and any concept can be individualized-so that there is great latitude in what can be brought into conjunction" (ibid., emphasis added). With Strathern, I wish to bring attention to the latitude or wide angularity of our conceptual habitus: commons, freedom, publicity, choice. Concepts all that appear to carry within their own sense of amplitude. Wide concepts for a world wide open. It would appear that in this epistemology it is hard not to look at the world with wide-angle binoculars.

\section{References}

Benkler, Yochai. 2006. The wealth of networks: How social production transforms markets and freedom. New Haven: Yale University Press. 
Boyle, James. 2003. "Foreword: The opposite of property?" Law and Contemporary Problems 66: 1-32.

Coleman, Gabriella E. and Alex Golub. 2008. "Hacker practice.” Anthropological Theory 8: 255-277.

Cornes, Richard and Todd Sandler. 1996. The theory of externalities, public goods, and club goods, Vol. 2. Cambridge: Cambridge University Press.

Corsín Jiménez, Alberto. 2008. "Introduction: Well-being's re-proportioning of social thought." In Culture and well-being: anthropological approaches to freedom and political ethics, edited by Alberto Corsín Jiménez, 1-32. London: Pluto Press.

- 2011. The strabismic polity: An anthropological optics of political modernity http://sites.google.com/site/acorsinjimenez/articles/strab_polity_110516.pdf?attr edirects $=0$.

Crook, Tony. 2007. Anthropological knowledge, secrecy and Bolivip, Papua New Guinea: exchanging skin. Oxford: British Academy/Oxford University Press.

David, Paul A. 2000. A tragedy of the public knowledge "commons". Global science, intellectual property and the digital technology boomerang. Stanford Institute for Economic Policy Research Discussion Paper Series, 2. Stanford University.

David, Paul A. and Dominique Foray. 2003. "Economic fundamentals of the knowledge society." Policy Futures in Education 1: 20-49.

Foray, Dominique. 2006. The economics of knowledge. Cambridge, Mass., and London: The MIT Press.

Frischmann, Brett M. and Mark A. Lemley 2006. "Spillovers." http://ssrn.com/abstract=898881.

Grootenboer, Hanneke. 2005. The rhetoric of perspective: Realism and illusionism in seventeenth-century Dutch still-life painting. Chicago and London: The University of Chicago Press.

Hess, Charlotte and Elinor Ostrom. 2003. "Ideas, artifacts, and facilities: information as a common-pool resource." Law and Contemporary Problems 66: 111-145.

Kelty, Christopher M. 2008. Two bits: the cultural significance of free software. Durham and London: Duke University Press.

Leach, James, Dawn Nafus and Bernhard Krieger 2009. "Freedom imagined: morality and aesthetics in open source software design.” Ethnos 74: 51-71.

Riles, Annelise. 2001. The network inside out. Ann Arbor: The University of Michigan Press.

Stiglitz, Joseph E. 1999. "Knowledge as a global public good." In Global public goods: International cooperation in the $21^{\text {st }}$ century, edited by Inge Kaul, Isabelle Grunberg, and Marc Stern, 308-324. New York: Oxford University Press. doi.org/10.1093/0195130529.001.0001. 
Strathern, Marilyn. 2005. Kinship, law and the unexpected: relatives are always a surprise. New York: Cambridge University Press.

- 2006. "Intellectual property and rights: an anthropological perspective." In Handbook of material culture, edited by Christopher Tilley, Webb Keane, Susanne Küchler, Michael Rowlands and Patricia Spyer, 447-462. London, Thousand Oaks and New Delhi: Sage Publications.

—. 2011. "Binary license." Common Knowledge 17: 87-103.

Viveiros de Castro, Eduardo. 2010. Metafísicas caníbales. Líneas de antropología postestructural (Spanish translation of Métaphysiques cannibales. Lignes d'anthropologie post-structurale.) Buenos Aires and Madrid: Katz Editores.

Wagner, Roy. 1977. “Analogic kinship: a Daribi example.” American Ethnologist 4: $623-642$.

\section{La parenté Daribi sous des angles perpendiculaires : une anthropologie en trompe l'oil}

Résumé : Quels sont les contours d'un « savoir " qui servirait à la fois de bien public ou commun et de source de prise de pouvoir ainsi que de liberté individuelle ? Cet article offre une analyse de l'organisation épistémologique d'une " économie de la connaissance " en passant un travail ethnographique sur le Free Software à travers un trompe l'œil espiègle, par le biais de l'œuvre classique de Roy Wagner sur la parenté Daribi. Il propose un modèle préliminaire pour penser la connaissance euro-américaine en tant que dispositif trompe l'œil elle-même.

Alberto Corsín Jiménez is Senior Scientist at the Spanish National Research Council. Previously he was Dean at Spain's School for Industrial Organization (EOI) and University Lecturer in the Anthropology of Organizations at the University of Manchester. He is the editor of Culture and well-being: Anthropological approaches to freedom and political ethics (Pluto, 2008) and The anthropology of organisations (Ashgate, 2007), and is currently revising a book manuscript for publication, provisionally titled The strabismic polity: An anthropological essay on the political optics of modernity. His areas of interest lie in the history and anthropological theory of knowledge practices, and in particular their contemporary expression in science/management/public encounters. 